\title{
MINIMUM STIFFNESS OF AN INTERMEDIATE SUPPORT FOR A BEAM TO MAXIMIZE ITS FUNDAMENTAL FREQUENCY
}

\author{
Mohamed Abdel-Basset Abdo \\ Lecturer, Civil Engineering Department, Faculty of Engineering, Assiut \\ University, Assiut, Egypt.
}

(Received July 4, 2006 Accepted July 27, 2006)

The concept to increase the fundamental natural frequency (below which no vibration could occur) of a structure as high as possible is commonly adopted to make the structure better in dynamic environment. Due to design limitations, the fundamental frequency of a beam can be increased via adding additional intermediate point supports. If the intermediate supports are rigid, the optimum locations of the supports should be at the nodal points of a higher vibration mode without the supports, and the fundamental frequency is correspondingly raised. For elastic supports, which often occurs in practice, the optimum locations are still the same as the case of rigid supports with no decrease in fundamental frequency provided that the support stiffness exceeds a certain minimum value. Indeed, the minimum stiffness prediction is very important in the design of beams, since the bracing or support materials can be reduced without any loss of performance. This paper investigates and discusses the minimum stiffness of an intermediate support through the span of a beam for maximum value of its fundamental frequency. In this study it is assumed that the intermediate support of the beam is provided through the span of the beam (at an interval of 0.05 of the span). The finite element technique is used in the analysis of a beam model with different end conditions. It is found that when the intermediate support is not at the optimum location, there exists a minimum stiffness of the support to give the fundamental frequency of the rigidly supported beam (such minimum stiffness phenomenon also occurs in the buckling of beams). Design curves are obtained to estimate the minimum stiffness of an intermediate support through the span of a beam and the corresponding fundamental frequency.

KEYWORDS: Minimum stiffness, intermediate support, maximum fundamental frequency and dynamic environment.

\section{INTRODUCTION}

Most civil structures such as multistory buildings, towers, bridges, and offshore platforms accumulate damage gradually during their service lives or suddenly during natural disasters. Monitoring or periodic inspection of structures provides 
updated information regarding the ability of the structure to continue to perform its desired function. Based on the monitored state, appropriate repair, rehabilitate, and/or strengthening of structures are decided to keep these structures operational and further to lengthen their lives. Because the cost for repair is much lower than the cost for reconstruction of new structures, repair and/or strengthening is vital for civil infrastructure facilities, which form the lifeline of our countries' economy.

Indeed, changes in structural physical properties (mass, damping and stiffness) will cause changes in its modal characteristics (resonant frequencies, mode shapes and modal damping), [1]. The most useful damage location methods (based on dynamic testing) are probably those using changes in resonant frequencies because frequency measurements can be quickly conducted and are often reliable. Another advantage is the global nature that allows the measurement points to be chosen to suit the test situation. Salawu [2] gave a literature review of the state of the art of damage detection using changes in natural frequency. Numerous studies have indicated that an increase in structural damage reflects a decrease in natural frequencies of the structure. So, strengthening of such structures is needed to maximize their frequencies. Indeed, the concept to increase the fundamental natural frequency or eigenvalue of a structure as high as possible is commonly adopted to make the structure better in dynamic environment. Adding and/or changing support positions are frequently used when the size or shape of the structure can not be altered due to design limitations. Actually, the beam is the main component of most civil structures, e.g., buildings, bridges, cranes, etc. So, the fundamental frequency (below which no vibration could occur) of a beam is of general significance.

The fundamental frequency can be increased if a beam has additional intermediate point supports. If the intermediate supports are rigid, Courant and Hilbert [3] showed that the optimum locations of the supports should be at the nodal points of a higher vibration mode without the supports, and the fundamental frequency is correspondingly raised. The situation becomes more complicated when the supports are not perfectly rigid, which often occurs in practice. For elastic supports, Akesson and Olhoff [4] demonstrated that the optimum locations are still the same as the case of rigid supports, with no decrease in fundamental frequency, provided that the support stiffness exceeds a certain minimum value. Such minimum stiffness phenomenon also occurs in the buckling of beams, [5]. Indeed, the minimum stiffness prediction is very important in the design of beams, since the bracing or support materials can be reduced without any loss of performance. There exist other literatures on the vibration of beams with internal elastic supports (e.g. references [6-10]). Among many researches, only references [2] and [10] are the sources which discussed the minimum stiffness. In reference [2], they used the finite element technique to find the stiffness criterion for the cantilever beam. On the other hand, Wang [10] presented the optimum location and the minimum stiffness of internal support for beams with other end conditions. He used the exact characteristic equation to compute the eigenfrequencies. However, for some reasons, the internal support may not be placed in the optimum location. Up till now, there is no literature about the minimum stiffness of internal supports through the span to maximize the corresponding fundamental frequencies.

The objective of this paper is to investigate and discuss the minimum stiffness of an intermediate support of a beam for maximum value of its fundamental frequency. The study includes not only the optimum locations but also various locations through 
the span of the beam (at an interval of 0.05 of the span). A careful numerical study is carried out by using the finite element method to analyze dynamic behaviour of a beam on an internal elastic support to obtain its minimum stiffness for maximum fundamental frequency. A comparison between analytical and numerical solutions is thoroughly studied to verify the accuracy of numerical results. Four steel beam models with different end conditions are investigated; 1) clamped-clamped, 2) simply-simply, 3) clamped-simply and 4) clamped-free.

\section{THEORETICAL BACKGROUND}

\subsection{Exact Characteristic Equations}

Consider a uniform thin beam with length $L$ and assume $x L$ is the distance from the left end of the beam. If the transverse displacement is $w(x) \cos (\omega t)$, the governing equation for vibration of a slender beam is [11]

$$
w^{\prime \prime \prime \prime}(x)-\lambda^{4} w=0,
$$

where $\lambda^{4}=\rho L^{4} \omega^{2} / D$ is the square of the normalized frequency, $\rho=$ mass per length, $\omega=$ frequency, $D=E I=$ flexural rigidity with $E$ and $I$ being the Young's modulus and the second moment of the cross section, respectively. The general solution to Eq.(1) is a linear combination of $\sinh (\lambda x), \cosh (\lambda x), \sin (\lambda x), \cos (\lambda x)$. The intermediate support is at $x=b$. Let the subscript $I$ denote the segment $0 \leq x \leq b$ and the subscript II denote the segment $b \leq x \leq 1$. Thus, the solution for segment $\boldsymbol{I}$ is

$$
\begin{aligned}
& w_{I}(x)=C_{1}[\sinh (\lambda x)-\sin (\lambda x)]+C_{2}[\cosh (\lambda x)-\cos (\lambda x)], \\
& w_{I}(x)=C_{1} \sinh (\lambda x)+C_{2} \sin (\lambda x), \\
& w_{I}(x)=C_{1}[\sinh (\lambda x)+\sin (\lambda x)]+C_{2}[\cosh (\lambda x)+\cos (\lambda x)],
\end{aligned}
$$

for clamped, simply supported and free left end conditions, respectively. Similarly, the solution for segment $\boldsymbol{I I}$ is

$$
\begin{gathered}
w_{I I}(x)=C_{3}\{\sinh [\lambda(x-1)]-\sin [\lambda(x-1)]\} \\
+C_{4}\{\cosh [\lambda(x-1)]-\cos [\lambda(x-1)]\}, \\
w_{I I}(x)=C_{3} \sinh [\lambda(x-1)]+C_{4} \sin [\lambda(x-1)], \\
w_{I I}(x)=C_{3}\{\sinh [\lambda(x-1)]+\sin [\lambda(x-1)]\} \\
+C_{4}\{\cosh [\lambda(x-1)]+\cos [\lambda(x-1)]\},
\end{gathered}
$$

for the above mentioned three kinds of right end conditions. At the location $x=b$ the two segments are matched for displacement, slope, moment but shear is affected by the spring support as follows:

$$
w_{I}(b)=w_{I I}(b),
$$




$$
\begin{aligned}
& w_{I}^{\prime}(b)=w_{I I}^{\prime}(b), \\
& w_{I}^{\prime \prime}(b)=w_{I I}^{\prime \prime}(b), \\
& w_{I}^{\prime \prime \prime}(b)-\gamma w_{I}(b)=w_{I I}^{\prime \prime \prime}(b) .
\end{aligned}
$$

Here, $\gamma=c L^{3} / D$ is the normalized support stiffness with $c=$ spring constant and $L$ and $D$ are as defined above. Equations (2) and (3) are then substituted into equations (4)-(7). For non-trivial solutions, exact characteristic equation is obtained. The frequency parameter $\lambda$ is then solved by a bisection algorithm to any desired accuracy. The analytical solutions are obtained using MATHEMATICA package [12].

In order to find the minimum stiffness of an intermediate support, the following scheme is used. First consider the beam with no intermediate support. From Eq.(2) and the appropriate boundary conditions on the right end, we obtain the second eigenfrequency, say $\lambda^{*}$. Using the corresponding eigenfunction, the single interior nodal location is determined, say at $b^{*}$. According to references [3] and [4], these are the maximum fundamental frequency and the optimum location of the interior beam support. The next step is to set $b=b^{*}$ and use the characteristic equation obtained from equations (2)-(7) to find the minimum stiffness such that $\lambda^{*}$ becomes the fundamental frequency.

Figure 1(a) shows the relationship between $\lambda$ and $\gamma$ for the clamped-clamped beam. Figure 1(b) shows the similar relationship for the simply-simply supported beam. The horizontal line $\left(\lambda^{*}\right)$ represents a mode independent of the stiffness, (antisymmetric mode). The slanted curve is another mode whose frequency increases with stiffness (symmetric mode). The lowest (fundamental frequency) becomes constant at the intersection of the two curves. The optimum location and the minimum stiffness for a various end conditions are given in Table 1, [10].

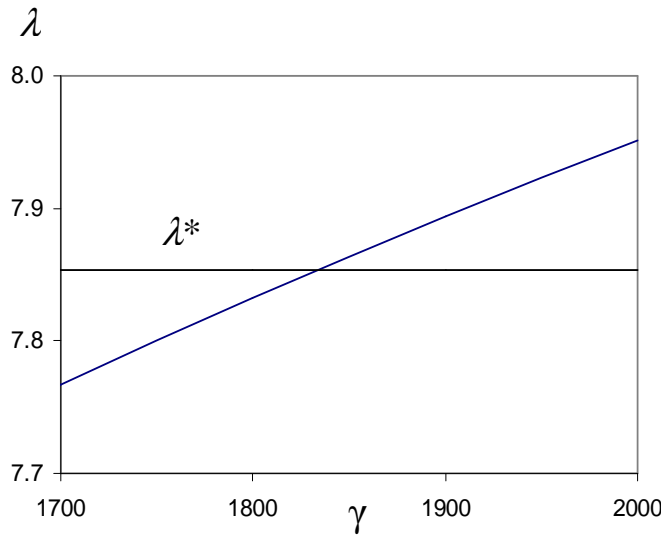

(a)



(b)

Figure 1: Analytical results of variation of the two lowest frequencies with respect to stiffness at $b^{*}=0.5$ : (a) clamped-clamped case; (b) simply-simply case 
Table 1: Optimum location $b^{*}$, minimum stiffness $V^{*}$ and maximum frequency $\lambda^{*}$ with various end conditions: $C=$ clamped, $S=$ simply supported, $F=$ free.

\begin{tabular}{|c|c|c|c|c|}
\hline Ends & C-C & S-S & C-S & C-F \\
\hline$b^{*}$ & 0.5000 & 0.5000 & 0.5575 & 0.7834 \\
$\lambda^{*}$ & 7.8532 & 6.2832 & 7.0686 & 4.6941 \\
$\gamma^{*}$ & 1834 & 995.9 & 1377 & 266.9 \\
\hline
\end{tabular}

\subsection{Accuracy of Numerical Results}

We consider a steel beam element to examine the above results. This example is quoted from a simulated study by Abdo [13]. The beam is assumed to have uniform cross sectional area and $60[\mathrm{~m}]$ length. The cross sectional area of the beam and the moments of inertia are, $A=0.07\left[\mathrm{~m}^{2}\right]$, and $I_{z}=0.040\left[\mathrm{~m}^{4}\right], I_{y}=0.001\left[\mathrm{~m}^{4}\right]$, respectively. The mechanical properties of the steel beam are, Young's modulus, $E=210$ [GPa], Poisson's ratio, $v=0.3$, and the density, $\rho=7,850\left[\mathrm{~kg} / \mathrm{m}^{3}\right]$. The modal frequencies of the beam are calculated numerically using the software package MARC/Mentat [14], [15]. Two-node beam element (element 52) with six degrees of freedom per node is used. The finite element model of the beam consists of 60 equal-length 2-D beam elements and 61 nodes. Figure 2 illustrates the finite element model of the steel beam.

To verify the accuracy of the numerical simulation, two cases of the beam will be studied; a clamped-clamped beam and a simply-simply supported beam. First, we consider the beam without any intermediate support. The eigenfrequencies of the beam structure is calculated for the two cases. The second eigenfrequency will be the fundamental frequency of a beam with one support at mid span. The next step is to provide the beam with an elastic support at mid span. A parametric study will be carried out to find the minimum stiffness of the middle support which provides the maximum fundamental frequency of the beam (the second eigenfrequency of the beam without any intermediate support). It is assumed that the elastic support has a translational spring which acts only in y-direction.

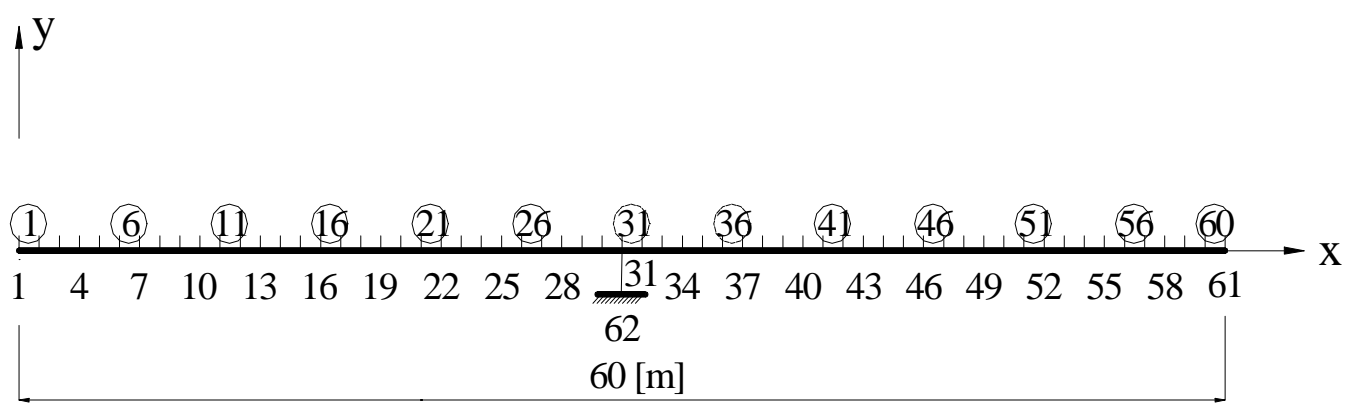

Figure 2: Finite element model of the steel beam with intermediate support. 
The relationships between $\lambda$ and $\gamma$ for the clamped-clamped beam and for the simply-simply supported beam are plotted in Fig. 3. Indeed, the results are in good agreement to those obtained analytically in Fig. 1. Table 2 lists the percentage error of the optimum location, the maximum frequency $\lambda^{*}$ and the minimum stiffness $\gamma^{*}$ for various end conditions. It is clear that the percentage error is less than $0.0003 \%$ for normalized frequency and less than $0.03 \%$ for normalized support stiffness. Therefore, the results are satisfactory for numerical investigation.

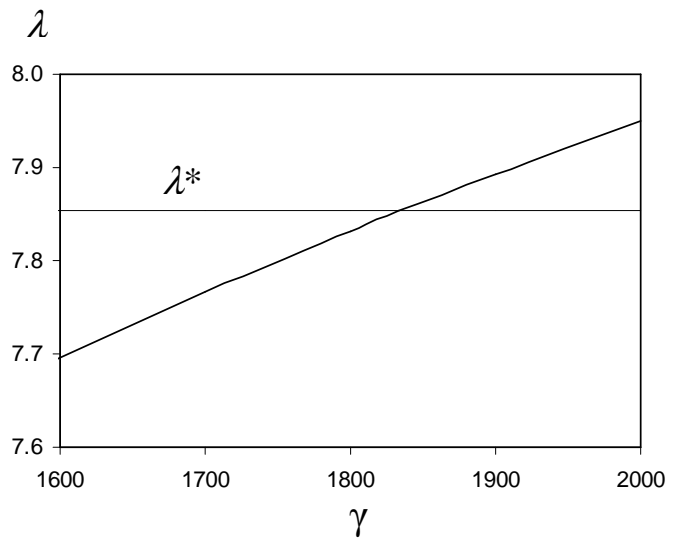

(a)

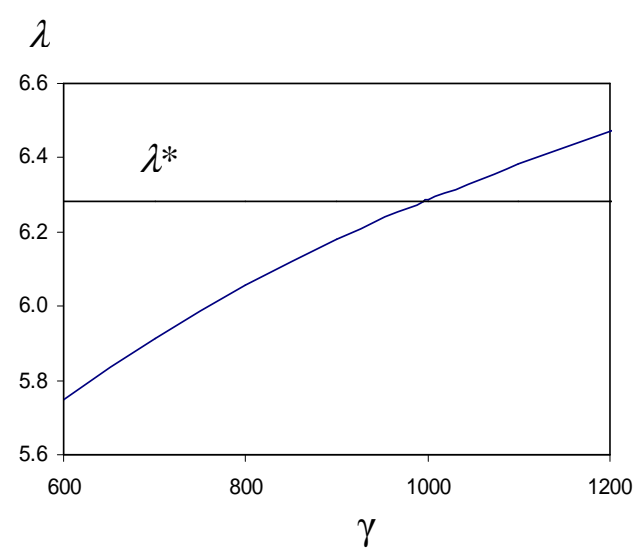

(b)

Figure 3: Numerical results of variation of the two lowest frequencies with respect to stiffness at $b^{*}=0.5$ : (a) clamped-clamped case; (b) simply-simply case.

Table (2): Percentage error of optimum location $b^{*}$, minimum stiffness $Y^{*}$ and maximum frequency $\lambda^{*}$ with various end conditions: $\mathrm{C}=$ clamped, $\mathrm{S}=$ simply supported.

\begin{tabular}{|c|c|c|c|}
\hline Ends & $b^{*}$ & $\lambda^{*}$ & $\gamma^{*}$ \\
\hline C-C & 0.000 & -0.00016 & -0.00273 \\
S-S & 0.000 & 0.00002 & 0.01988 \\
C-S & 0.000 & -0.00023 & 0.02762 \\
C-F & 0.000 & -0.00015 & 0.01873 \\
\hline
\end{tabular}

\section{RESULTS AND DISCUSSIONS}

Let us consider the beam shown in Fig. 2 with physical and mechanical properties as mentioned in Section 2.2. The eigenfrequencies are studied for the four cases of the beam; clamped-clamped, simply-simply, clamped-simply and clampedfree. First, we consider a rigid support at an interval of 0.05 of the span for each case of the beam and calculate the corresponding fundamental frequency of the rigidly 
supported beam, say $\lambda^{*}$. Next, we replace the rigid support with an elastic one at the same position. Then, the relationship between the normalized frequency, $\lambda$ and the normalized stiffness of the elastic support $\gamma$ is plotted to determine the minimum stiffness of the intermediate support which provides the fundamental frequency of the rigidly supported beam.

\subsection{Clamped-Clamped Beam}

Let the beam be of length $L$ and $x$ be the distance from the left end support and the beam be clamped-clamped at both left and right ends. Because of symmetry, only one half of the beam is investigated. The elastic intermediate support is provided at an interval of 0.05 of the span. The relationship between the normalized frequency $(\lambda)$ and the normalized stiffness of the elastic support $(\gamma)$ is plotted to determine the minimum stiffness of the intermediate support which provides the fundamental frequency of the rigidly supported beam.

Figure 4 (a, b, c and $\mathbf{d}$ ) show the relationship between $\lambda$ and $\gamma$ for the clamped-clamped beam at $\mathrm{x}=0.1 L, 0.2 L, 0.3 L$ and $0.4 L$, respectively. Indeed, because the values of the normalized stiffness (on $x$-axis) are high, they are plotted in log-scale. In Fig. 4, the horizontal line $\lambda^{*}$, represents the fundamental frequency of the rigidly supported beam at the corresponding position. It is shown that the frequency increases with stiffness until it reaches the beam fundamental frequency at the intersection of the two curves. Also, it can be seen that frequency is sensitive to changes in stiffness for small values of the support stiffness but not so sensitive near the fundamental frequency.

Table 3 lists the values of the normalized frequency $\left(\lambda^{*}\right)$ and normalized support stiffness $\left(\gamma^{*}\right)$ with respect to the distance from the clamped left edge of the beam. Also, Figs. 5 and $\mathbf{6}$ plot respectively, the minimum stiffness of an intermediate support and the corresponding maximum fundamental frequencies through the span of a clamped-clamped beam. The horizontal line $\left(\lambda_{0}\right)$ represents the fundamental frequency of a clamped-clamped beam without an intermediate support. It is apparent that the optimum location (at which, we can obtain maximum fundamental frequency of the beam with minimum stiffness of an elastic support) of an intermediate support is at mid span of the beam. It is of interest to mention that the percentage increase in the normalized fundamental frequency of a clamped-clamped beam with intermediate support with sufficient stiffness at the optimum location is $66.03 \%$ greater than that without intermediate support. Indeed, it can be easily seen that the corresponding minimum stiffness of the intermediate elastic support increases with being far from the mid span towards the end supports of the beam. However, the corresponding fundamental frequency deceases as the intermediate support moves far from the mid span towards the end supports and approaches that of the unstiffened beam near the end supports of the beam. So, intermediate elastic supports not at the optimum location require much stiffness and provide less fundamental frequency and not so useful near the end supports. 


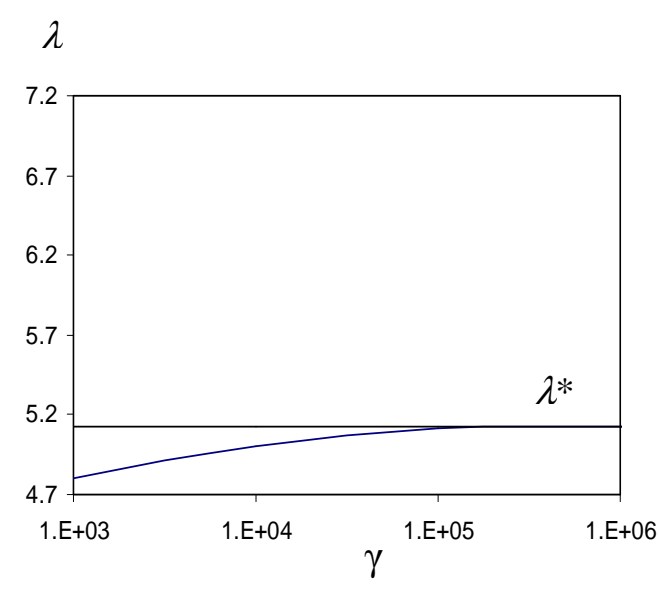

(a)

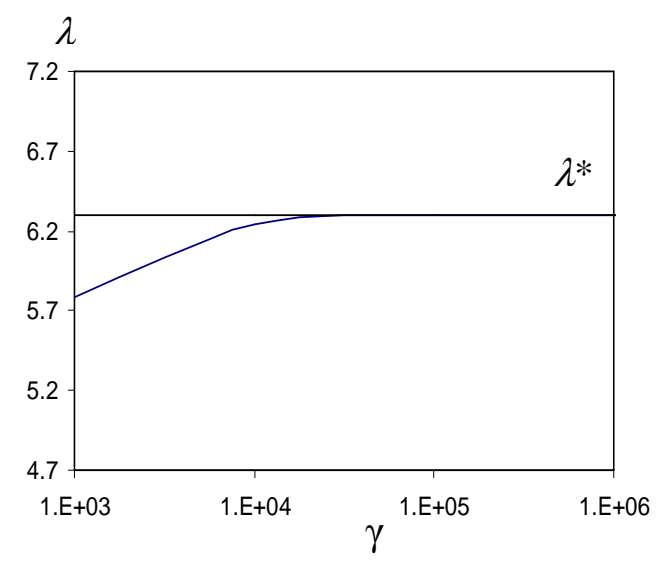

(c)

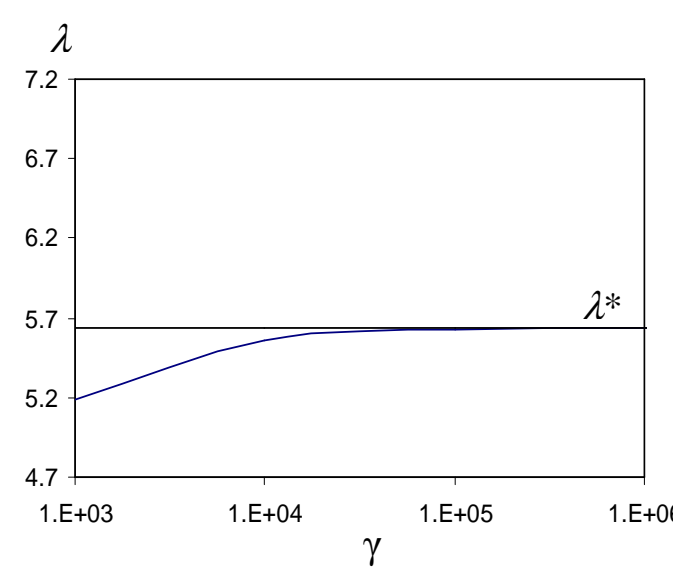

(b)



(d)

Figure 4: Numerical results of variation of the frequency with respect to intermediate support stiffness: (a) $\mathrm{x}=0.1 L$; (b) $\mathrm{x}=0.2 L$; (c) $\mathrm{x}=0.3 L$; (d) $\mathrm{x}=0.4 L$

Table 3: Normalized frequency $\left(\lambda^{*}\right)$ and normalized support stiffness $\left(\gamma^{*}\right)$ with respect to the distance from the left edge of the clamped-clamped beam.

\begin{tabular}{|c|c|c|c|c|c|c|c|c|c|c|}
\hline$x / L$ & 0.05 & 0.10 & 0.15 & 0.20 & 0.25 & 0.30 & 0.35 & 0.40 & 0.45 & 0.50 \\
\hline$\lambda *$ & 4.916 & 5.127 & 5.366 & 5.637 & 5.946 & 6.298 & 6.699 & 7.146 & 7.600 & 7.853 \\
$\gamma^{*}$ & $\begin{array}{c}2.250 \\
\mathrm{e} 6\end{array}$ & $\begin{array}{c}7.190 \\
\mathrm{e} 5\end{array}$ & $\begin{array}{c}4.090 \\
\mathrm{e} 5\end{array}$ & $\begin{array}{c}2.955 \\
\mathrm{e} 5\end{array}$ & $\begin{array}{c}2.415 \\
\mathrm{e} 5\end{array}$ & $\begin{array}{c}2.115 \\
\mathrm{e} 5\end{array}$ & $\begin{array}{c}1.880 \\
\mathrm{e} 5\end{array}$ & $\begin{array}{c}1.555 \\
\mathrm{e} 5\end{array}$ & $\begin{array}{c}8.550 \\
\mathrm{e} 4\end{array}$ & $\begin{array}{c}1.834 \\
\mathrm{e} 3\end{array}$ \\
\hline
\end{tabular}






Figure 5: Minimum normalized stiffness of an intermediate support through the span to obtain the maximum fundamental frequency of a clamped-clamped beam.

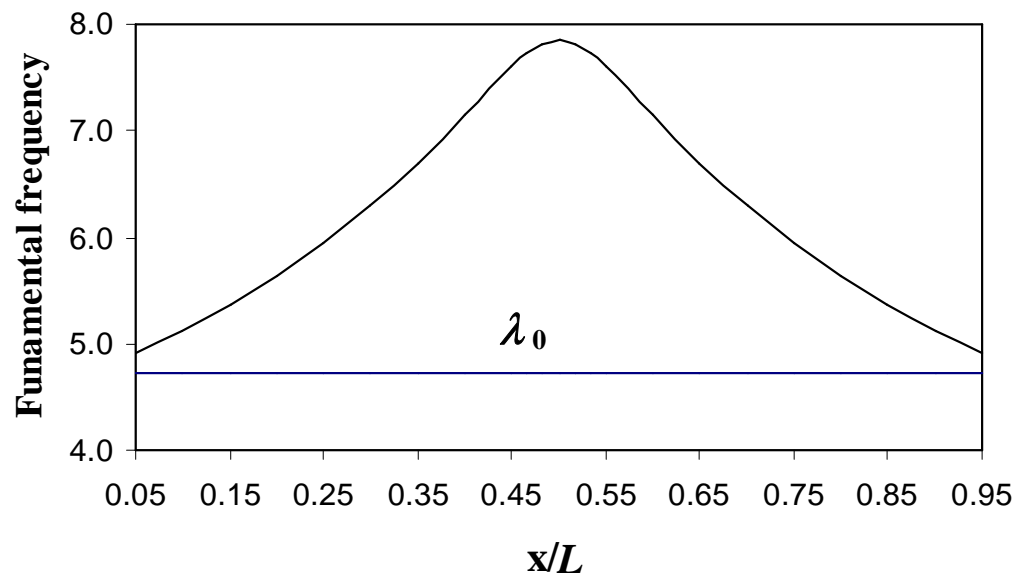

Figure 6: Maximum normalized fundamental frequency of a clamped-clamped beam supported on an intermediate rigid support through the span.

\subsection{Simply-Simply Supported Beam}

In the same manner, let the beam be of length $L$ and $x$ be the distance from the left end support and the beam be simply-simply supported at both left and right ends. Because of symmetry, only one half of the beam is investigated. The elastic intermediate support is provided at an interval of 0.05 of the span. The relationship between the normalized frequency $(\lambda)$ and the normalized stiffness of the elastic support $(\gamma)$ is plotted to determine the minimum stiffness of the intermediate support which provides the fundamental frequency of the rigidly supported beam. Indeed, the plots at each $0.05 \mathrm{~L}$ of the span are similar to those obtained in Fig. 4 for the clampedclamped beam. 
Table 4 lists the values of the normalized frequency $(\lambda *)$ and normalized support stiffness $\left(\gamma^{*}\right)$ with respect to the distance from the left edge of the beam. Also, Figs. 7 and 8 illustrate respectively the minimum stiffness of an intermediate support and the corresponding maximum fundamental frequencies through the span of a simply-simply supported beam. The horizontal line $\left(\lambda_{0}\right)$ represents the fundamental frequency of a simply- simply supported beam without an intermediate support. Again, it is clear that the optimum location of an intermediate support is at mid span of the beam. It is of interest to note that the percentage increase in the normalized fundamental frequency of a simply-simply supported beam with intermediate support with sufficient stiffness at the optimum location is $100.0 \%$ greater than that without intermediate support. Figure 7 shows that the minimum stiffness of the intermediate elastic support decreases as the intermediate support goes far from the end support and vice-versa. The variation of normalized stiffness is large near the end support $(0.05 \mathrm{~L}$ to $0.15 L$ ), becomes small in the range $(0.15 L$ to $0.40 L)$ and becomes steep near the middle of the span $(0.40 L-0.50 L)$. On the other hand, Fig. 8 shows that the fundamental frequency increases as the intermediate support goes far from the end support to the middle of the beam (optimum location). Again, if the elastic support is not provided at the mid span, we obtain less fundamental frequency which requires much stiffness of the intermediate support.

Table 4: Normalized frequency $\left(\lambda^{*}\right)$ and normalized support stiffness $\left(\gamma^{*}\right)$ with respect to the distance from the left edge of the simply-simply supported beam.

\begin{tabular}{|c|c|c|c|c|c|c|c|c|c|c|}
\hline$x / L$ & 0.05 & 0.10 & 0.15 & 0.20 & 0.25 & 0.30 & 0.35 & 0.40 & 0.45 & 0.50 \\
\hline$\lambda *$ & 4.065 & 4.224 & 4.407 & 4.616 & 4.855 & 5.129 & 5.439 & 5.780 & 6.111 & 6.283 \\
$\gamma^{*}$ & $\begin{array}{c}1.070 \\
\text { e6 }\end{array}$ & $\begin{array}{c}3.580 \\
\text { e5 }\end{array}$ & $\begin{array}{c}2.125 \\
\text { e5 }\end{array}$ & $\begin{array}{c}1.580 \\
\text { e5 }\end{array}$ & $\begin{array}{c}1.330 \\
\text { e5 }\end{array}$ & $\begin{array}{c}1.183 \\
\text { e5 }\end{array}$ & $\begin{array}{c}1.050 \\
\text { e5 }\end{array}$ & $\begin{array}{c}8.435 \\
\text { e4 }\end{array}$ & $\begin{array}{c}4.235 \\
\text { e4 }\end{array}$ & $\begin{array}{c}9.961 \\
\text { e2 }\end{array}$ \\
\hline
\end{tabular}

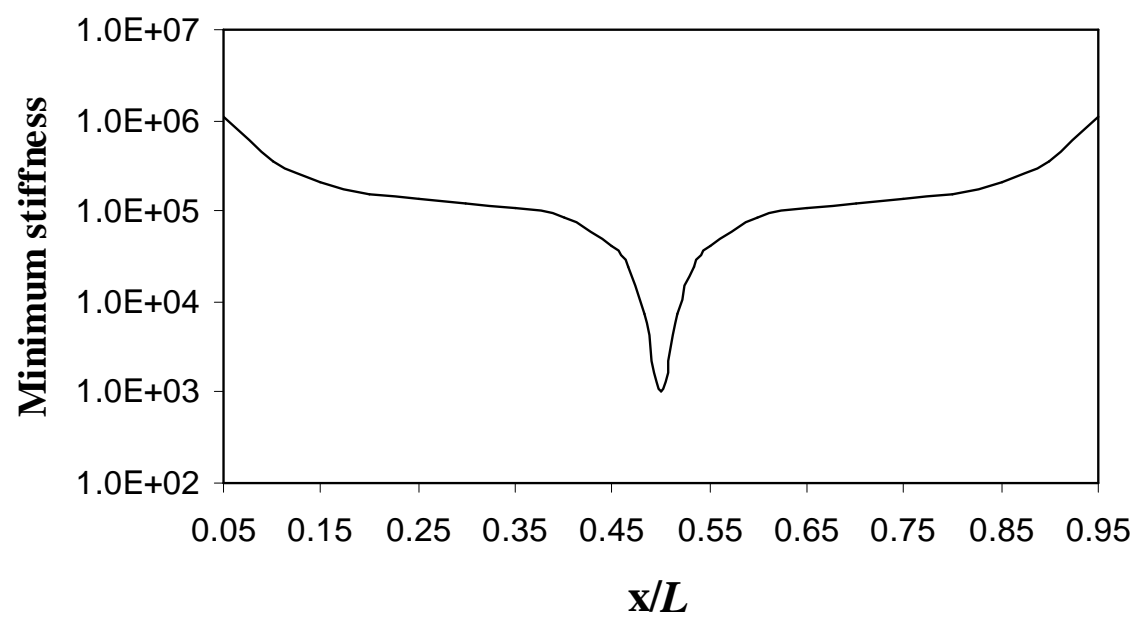

Figure 7: Minimum normalized stiffness of an intermediate support through the span to obtain the maximum fundamental frequency of a simply-simply supported beam. 


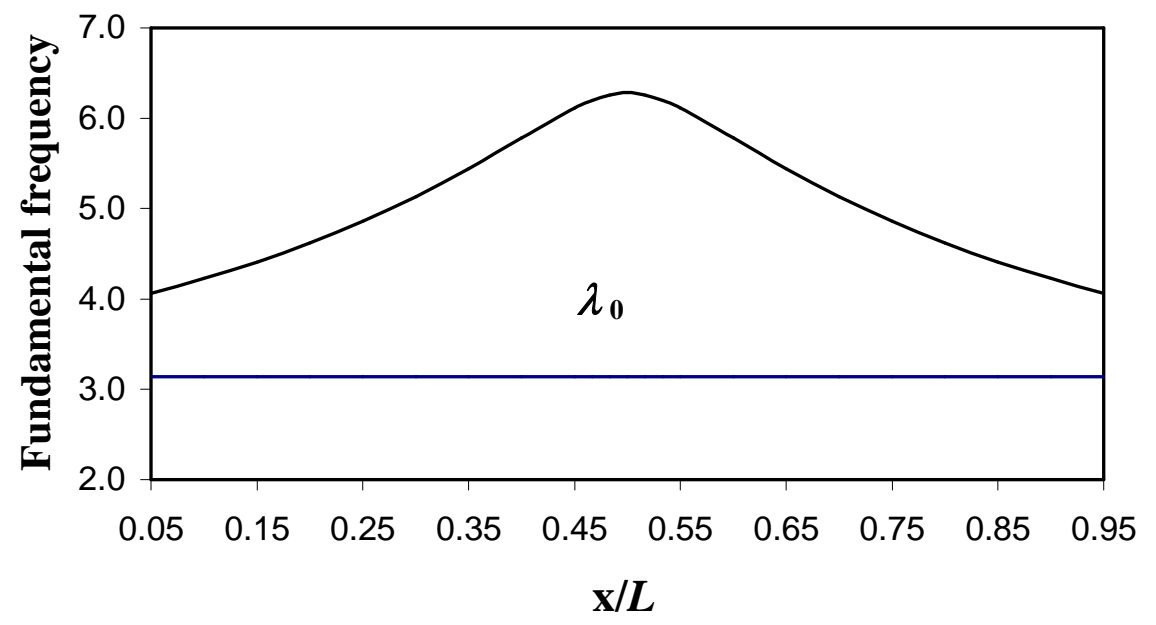

Figure 8: Maximum normalized fundamental frequency of a simply-simply supported beam supported on an intermediate rigid support through the span .

\subsection{Clamped-Simply Supported Beam}

In the same manner, let the beam be of length $L$ and $x$ be the distance from the left end support. Assume the beam to be clamped at the left end and simply supported at right end. The elastic intermediate support is provided at an interval of 0.05 of the span in addition to the optimum location of the intermediate support at $0.5575 \mathrm{~L}$. The relationship between the normalized frequency $(\lambda)$ and the normalized stiffness of the elastic support $(\gamma)$ is plotted to determine the minimum stiffness of the intermediate support which provides the fundamental frequency of the rigidly supported beam. Indeed, the plots at the intermediate supports (at an interval of $0.05 \mathrm{~L}$ ) are similar to those obtained in Fig. $\mathbf{4}$ for the clamped-clamped beam.

Table 5 lists the values of the normalized frequency $(\lambda *)$ and normalized support stiffness $\left(\gamma^{*}\right)$ with respect to the distance from the clamped edge of the beam. Also, Figs. $\mathbf{9}$ and $\mathbf{1 0}$ show respectively the minimum normalized stiffness of an intermediate support and the corresponding maximum normalized fundamental frequencies with respect to the distance from the clamped edge of the clamped-simply supported beam. The horizontal line $\left(\lambda_{0}\right)$ represents the fundamental frequency of a beam without an intermediate support. It is clear that the optimum location of an intermediate support is at $0.5575 \mathrm{~L}$ from the clamped edge. Figure 9 shows that the minimum stiffness of the intermediate elastic support increases with being far from the optimum location towards the end supports. On the other hand, Fig. 10 illustrates that the fundamental frequency decreases as the intermediate support goes far from the optimum location towards the end supports of the beam. Therefore, if the elastic support is not provided at the optimum location, we obtain less fundamental frequency which requires much stiffness of the intermediate support (many times that required at 
the optimum location). It is of interest to mention that the percentage increase in the normalized fundamental frequency of a clamped-simply supported beam with intermediate support with sufficient stiffness at the optimum location is $80.02 \%$ greater than that without intermediate support.

Table 5: Normalized frequency $\left(\lambda^{*}\right)$ and normalized support stiffness $\left(V^{*}\right)$ with respect to the distance from the clamped edge of the clamped-simply supported beam.

\begin{tabular}{|c|c|c|c|c|c|c|c|c|c|c|}
\hline$x / L$ & 0.05 & 0.10 & 0.15 & 0.20 & 0.25 & 0.30 & 0.35 & 0.40 & 0.45 & 0.50 \\
\hline$\lambda *$ & 4.080 & 4.254 & 4.450 & 4.672 & 4.924 & 5.212 & 5.542 & 5.920 & 6.345 & 6.783 \\
$\gamma^{*}$ & $\begin{array}{c}2.180 \\
\mathrm{e} 6\end{array}$ & $\begin{array}{c}6.780 \\
\mathrm{e} 5\end{array}$ & $\begin{array}{c}3.760 \\
\mathrm{e} 5\end{array}$ & $\begin{array}{c}2.658 \\
\mathrm{e} 5\end{array}$ & $\begin{array}{c}2.145 \\
\mathrm{e} 5\end{array}$ & $\begin{array}{c}1.878 \\
\mathrm{e} 5\end{array}$ & $\begin{array}{c}1.720 \\
\mathrm{e} 5\end{array}$ & $\begin{array}{c}1.584 \\
\mathrm{e} 5\end{array}$ & $\begin{array}{c}1.360 \\
\mathrm{e} 5\end{array}$ & $\begin{array}{c}8.150 \\
\mathrm{e} 4\end{array}$ \\
\hline
\end{tabular}

\begin{tabular}{|c|c|c|c|c|c|c|c|c|c|c|}
\hline$x / L$ & 0.55 & 0.5575 & 0.60 & 0.65 & 0.70 & 0.75 & 0.80 & 0.85 & 0.90 & 0.95 \\
\hline$\lambda^{*}$ & 7.059 & 7.069 & 6.917 & 6.567 & 6.202 & 5.869 & 5.575 & 5.317 & 5.092 & 4.897 \\
$\gamma^{*}$ & $\begin{array}{c}3.588 \\
\text { e3 }\end{array}$ & $\begin{array}{c}1.378 \\
\text { e3 }\end{array}$ & $\begin{array}{c}4.540 \\
\text { e4 }\end{array}$ & $\begin{array}{c}1.005 \\
\text { e5 }\end{array}$ & $\begin{array}{c}1.295 \\
\text { e5 }\end{array}$ & $\begin{array}{c}1.515 \\
\text { e5 }\end{array}$ & $\begin{array}{c}1.806 \\
\text { e5 }\end{array}$ & $\begin{array}{c}2.380 \\
\text { e5 }\end{array}$ & $\begin{array}{c}3.890 \\
\text { e5 }\end{array}$ & $\begin{array}{c}1.118 \\
\text { e6 }\end{array}$ \\
\hline
\end{tabular}



Figure 9: Minimum normalized stiffness of an intermediate support through the span to obtain the maximum fundamental frequency of a clamped-simply supported beam. 


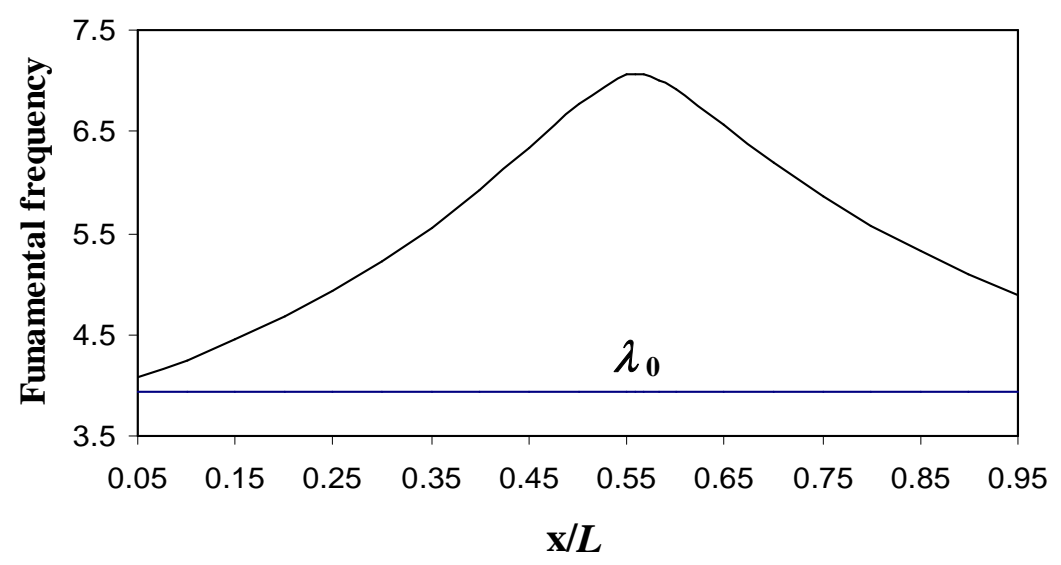

Figure 10: Maximum normalized fundamental frequency of a clamped-simply supported beam supported on an intermediate rigid support through the span.

\subsection{Clamped-Free Beam}

In the same manner, let the beam be of length $L$ and $x$ be the distance from the left end support. Assume the beam to be clamped at the left end and free at right end. The elastic intermediate support is provided at an interval of 0.05 of the span in addition to the optimum location of the intermediate support at $0.7834 \mathrm{~L}$. The relationship between the normalized frequency $(\lambda)$ and the normalized stiffness of the elastic support $(\gamma)$ is plotted to determine the minimum stiffness of the intermediate support which provides the fundamental frequency of the rigidly supported beam. Indeed, the plots at the intermediate supports (at an interval of $0.05 \mathrm{~L}$ ) are similar to those obtained in Fig. 4 for the clamped-clamped beam.

Table 6 lists the values of the normalized frequency $(\lambda *)$ and normalized support stiffness $\left(\gamma^{*}\right)$ with respect to the distance from the clamped edge of the beam. Also, Figs. 11 and 12 show respectively the minimum normalized stiffness of an intermediate support and the corresponding maximum normalized fundamental frequencies with respect to the distance from the clamped edge of the clamped-free beam. The horizontal line $\left(\lambda_{0}\right)$ represents the fundamental frequency of a clamped-free beam without an intermediate support. It is clear that the optimum location of an intermediate support is at $0.7834 \mathrm{~L}$ from the clamped edge. Also, the minimum stiffness of the intermediate elastic support increases with being far from the optimum location towards the clamped support or the free edge. The maximum value of the normalized stiffness is near the clamped edge. On the other hand, it can be seen that the fundamental frequency decreases as the intermediate support goes far from the optimum location towards the clamped support or the free edge of the beam. The minimum value of the frequency is obtained when the elastic support is near the clamped edge at which the value approaches that of the beam without an intermediate support. It is interesting to mention that the percentage increase in the normalized fundamental frequency of a clamped-free beam with intermediate support with sufficient stiffness at the optimum location is $150.34 \%$ greater than that without intermediate support. 
Table 6: Normalized frequency $\left(\lambda^{*}\right)$ and normalized support stiffness $\left(\gamma^{*}\right)$ with respect to the distance from the clamped edge of the clamped-free beam.

\begin{tabular}{|c|c|c|c|c|c|c|c|c|c|c|}
\hline$x / L$ & 0.05 & 0.10 & 0.15 & 0.20 & 0.25 & 0.30 & 0.35 & 0.40 & 0.45 & 0.50 \\
\hline$\lambda *$ & 1.948 & 2.028 & 2.117 & 2.215 & 2.324 & 2.447 & 2.586 & 2.745 & 2.928 & 3.140 \\
$\gamma^{*}$ & $\begin{array}{c}1.960 \\
\mathrm{e} 6\end{array}$ & $\begin{array}{c}5.465 \\
\mathrm{e} 5\end{array}$ & $\begin{array}{c}2.720 \\
\mathrm{e} 5\end{array}$ & $\begin{array}{c}1.722 \\
\mathrm{e} 5\end{array}$ & $\begin{array}{c}1.250 \\
\mathrm{E} 5\end{array}$ & $\begin{array}{c}9.920 \\
\mathrm{e} 4\end{array}$ & $\begin{array}{c}8.450 \\
\mathrm{e} 4\end{array}$ & $\begin{array}{c}7.470 \\
\mathrm{e} 4\end{array}$ & $\begin{array}{c}6.940 \\
\mathrm{e} 4\end{array}$ & $\begin{array}{c}6.630 \\
\mathrm{E} 4\end{array}$ \\
\hline
\end{tabular}

\begin{tabular}{|c|c|c|c|c|c|c|c|c|c|c|c|}
\hline$x / L$ & 0.55 & 0.60 & 0.65 & 0.70 & 0.75 & 0.783 & 0.80 & 0.85 & 0.90 & 0.95 & 1.00 \\
\hline$\lambda *$ & 3.389 & 3.681 & 4.018 & 4.372 & 4.637 & 4.694 & 4.680 & 4.546 & 4.344 & 4.130 & 3.925 \\
$\gamma^{*}$ & $\begin{array}{c}6.430 \\
\mathrm{e} 4\end{array}$ & $\begin{array}{c}6.135 \\
\mathrm{e} 4\end{array}$ & $\begin{array}{c}5.389 \\
\mathrm{e} 4\end{array}$ & $\begin{array}{c}3.475 \\
\mathrm{E} 4\end{array}$ & $\begin{array}{c}7.125 \\
\mathrm{e} 3\end{array}$ & $\begin{array}{c}2.670 \\
\mathrm{e} 2\end{array}$ & $\begin{array}{c}1.417 \\
\mathrm{e} 3\end{array}$ & $\begin{array}{c}1.007 \\
\mathrm{e} 4\end{array}$ & $\begin{array}{c}1.537 \\
\mathrm{e} 4\end{array}$ & $\begin{array}{c}1.620 \\
\mathrm{e} 4\end{array}$ & $\begin{array}{c}1.457 \\
\mathrm{e} 4\end{array}$ \\
\hline
\end{tabular}

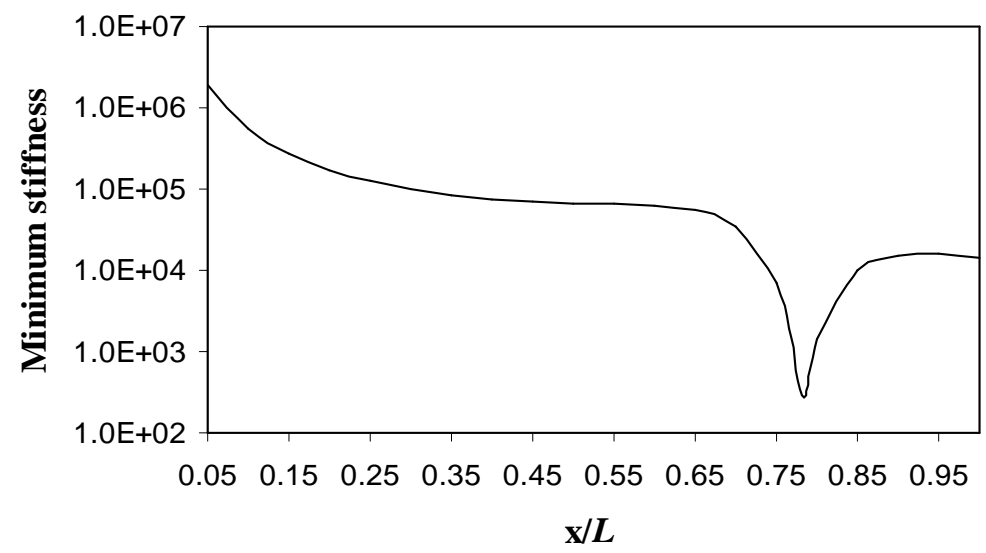

Figure 11: Minimum normalized stiffness of an intermediate support through the span to obtain the maximum fundamental frequency of a clamped-free beam

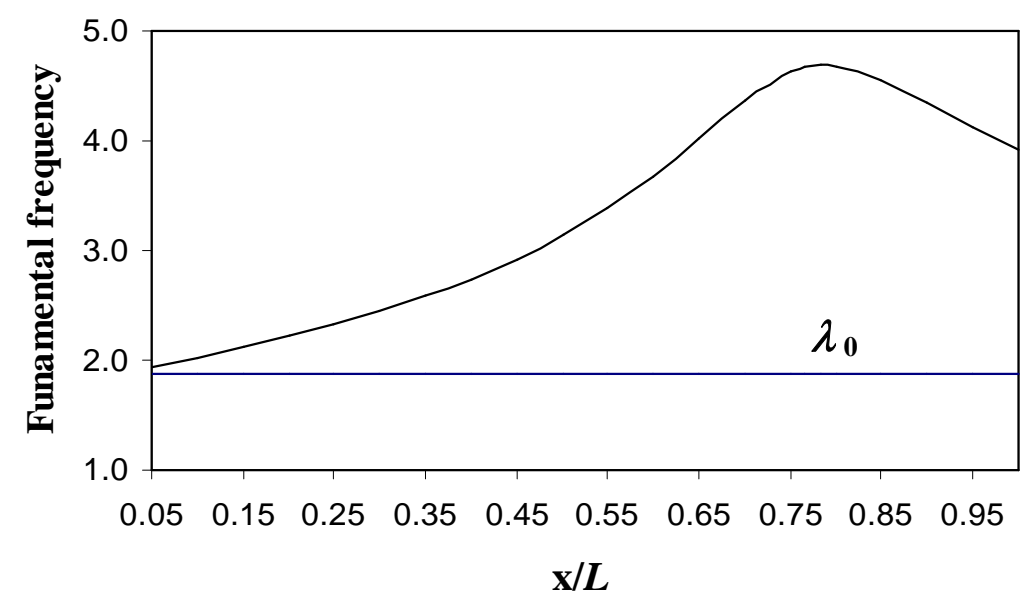

Figure 12: Maximum normalized fundamental frequency of a clamped-free beam supported on an intermediate rigid support through the span. 


\section{CONCLUSIONS}

The concept to increase the fundamental natural frequency or eigenvalue of a structure is commonly adopted to improve the dynamic performance of the structure. This paper investigates and discusses the minimum stiffness of an intermediate support of a beam for maximum value of its fundamental frequency. The study includes not only the optimum location of the intermediate support but also various locations through the span of the beam. Four cases of a steel beam model are investigated; 1) clamped-clamped, 2) simply-simply, 3) clamped-simply and 4) clamped-free. A parametric study is carried out to determine the minimum stiffness of the intermediate support which provides the fundamental frequency of the rigidly supported beam at an interval of 0.05 of the span.

Based on the above results, it can be concluded that at the optimum location of an intermediate support, we can obtain maximum fundamental frequency of the beam with minimum stiffness of the intermediate support. Indeed, the optimum location depends on the boundary conditions of the beam. It is of interest to mention that the percentage increase in the normalized fundamental frequency of providing a beam with an intermediate support at the optimum location with sufficient stiffness are $66.03 \%$, $100 \%, 80.02 \%$ and $150.34 \%$ greater than those without intermediate support for clamped-clamped, simply-simply, clamped-simply and clamped-free beams, respectively. When the intermediate support is not at the optimum location, there exists a certain minimum stiffness of the support to give the fundamental frequency of the rigidly supported beam. Such minimum stiffness phenomenon also occurs in the buckling of beams. The normalized fundamental frequency is deceased as the intermediate support is moved far from the optimum location with minimum value near the end supports. However, the corresponding minimum stiffness of the intermediate elastic support increases greatly as the intermediate support is moved far from the optimum location with maximum value at the end support(s). So, to make full use of an intermediate elastic support, it should be provided at the optimum location of the beam or very near to it, otherwise stiffer support is required with less fundamental frequency. Finally, this work provides an important guide for designers to improve the dynamic performance of beams with different end conditions via adding and/or changing support positions with minimum stiffness prediction.

\section{REFERENCES}

[1] Ewins, D. J.: "Modal Testing: THeOry And Practice", Wiley, New York, 313 pp., (1984).

[2] Salawu, O. S.: "Detection of Structural Damage through Changes in FREQUENCY", A review, J. Engineering Structures, Vol. 19, No.9, pp. 718-723, (1997).

[3] Courant, R. and Hilbert, D.: "Methods of Mathematical Physics", Vol. 1, New York: Interscience, Chapter 5, (1953).

[4] Akesson, B. and Olhoff, N.: "Minimum STIFFNESS OF OPTIMALLY LOCATED SUPPORTS FOR MAXIMUM VALUE OF BEAM EIGENFREQUENCIES", J. Sound and Vibration, Vol. 120, No. 2, pp. 457-463, (1988).

[5] Timoshenko, S. P., and Gere, J. M.: "TheORY OF ElASTiC STABiLity", New York: McGraw-Hill, Chapter 2, (1961). 
[6] Maurizi, M. J. and Rossit, D. V. B.: "FrEe VIBRATION OF A CLAMPED-CLAMPED BEAM WITH AN INTERMEDIATE ELASTIC SUPPORT", J. Sound and Vibration, Vol. 119, No. 1, pp. 173-176, (1987).

[7] Rao, C. K.: "FREQUENCY ANALYSIS OF CLAMPED-CLAMPED UNIFORM BEAMS WITH INTERMEDIATE ELASTIC SUPPORT", J. Sound and Vibration, Vol. 133, No. 2, pp. 502-509, (1989).

[8] Kulka, S.: "THE GREEN FUNCTION METHOD IN FREQUENCY ANALYSIS OF A BEAM WITH INTERMEDIATE ELASTIC SUPPORTS", J. Sound and Vibration, Vol. 149, No. 1, pp. 154-159, (1991).

[9] Won, K. M. and Park, Y. S.: "OPTIMAL SUPPORT POSITIONS FOR A STRUCTURE TO MAXIMIZE ITS FUNDAMENTAL NATURAL FREQUENCY", J. Sound and Vibration, Vol. 213, No. 5, pp. 801-812, (1998).

[10] Wang, C. Y.: "MINIMUM STIFFNESS OF AN INTERNAL ELASTIC SUPPORT TO MAXIMIZE THE FUNDAMENTAL FREQUENCY OF A VIBRATING BEAM", J. Sound and Vibration, Vol. 259, No. 1, pp. 229-232, (2003).

[11] Thomson, W. T.: "TheORY OF VibRATION WiTH APPLICATION", 3rd edition, Englewood Cliffs, New Jersey, 467 pp., (1988).

[12] MATHEMATICA version 4, STEPHEN WOLFRAM, (2000).

[13] Abdo, M. A.-B., "COMParative Study of CuRVATURE TeChniques Used IN DAMAGE IDENTIFICATION", International Conference on Structural \& Geotechnical Engineering and Construction Technology, IC-SGECT '04, Mansoura, Egypt, pp. 73-86, (2004).

[14] MARC Analysis Research Corporation, Volumes; A, B, and C, Version 2001, (2001).

[15] MARC Analysis Research Corporation, Mentat User's Guide, Version 2001, (2001).

\section{أقل كزازة لاعامة داخلية لكمرة لتكبير قيمة التردد الطبيعى الأسساسى لها}

إن فكرة زيادة قيمة التردد الطبيعى الأساسى (fundamental frequency) لمنشـأ

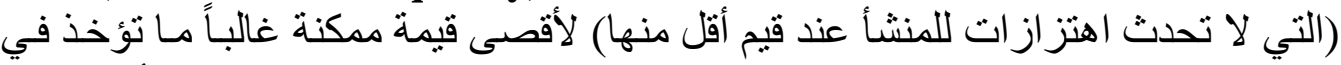

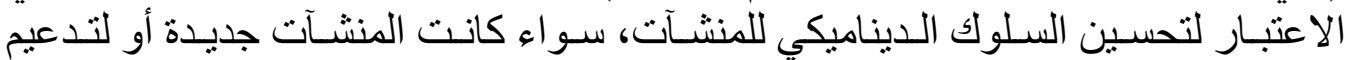

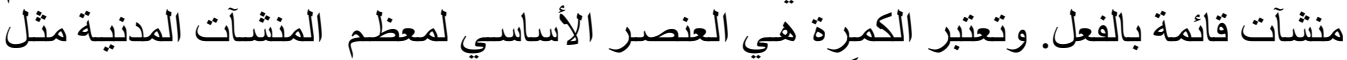





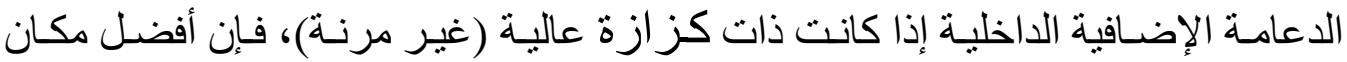

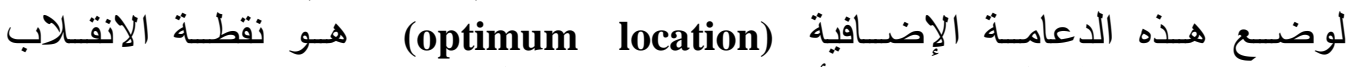

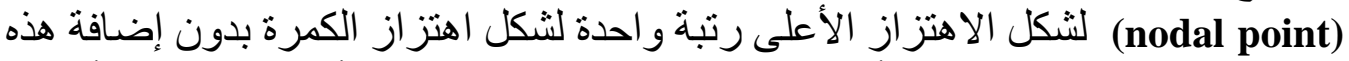



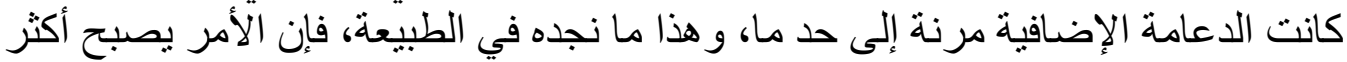

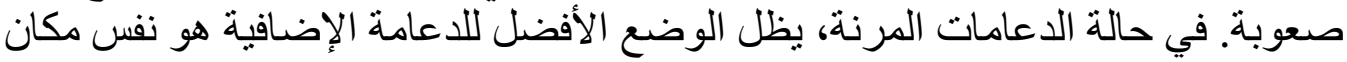


الدعامة غير المرنة وذللك بشرط ألا تقل كز ازة الدعامة المرنة عن حد معين. وقد وجد أن





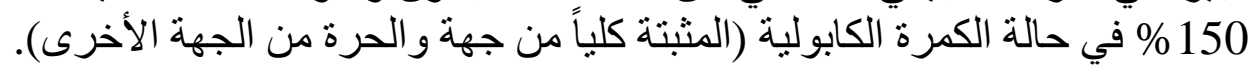



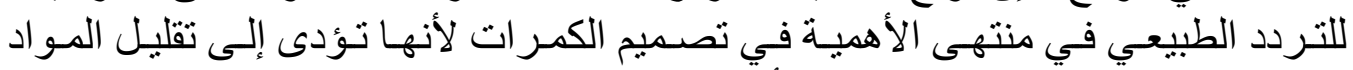

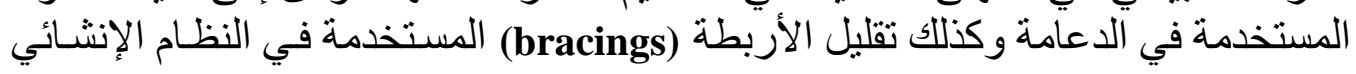

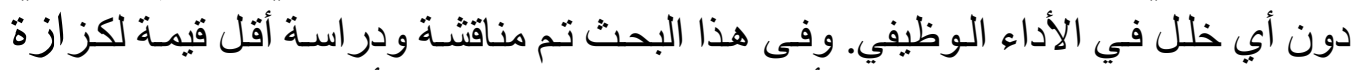



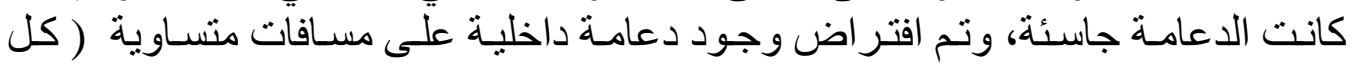

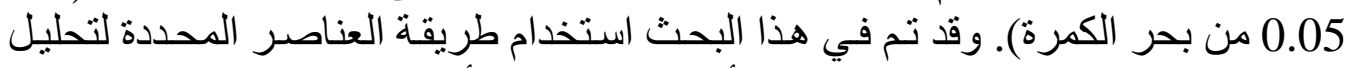

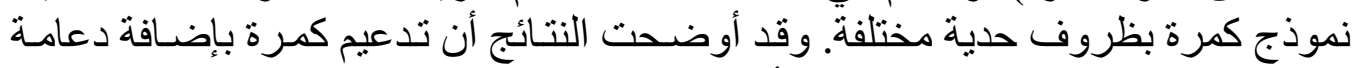

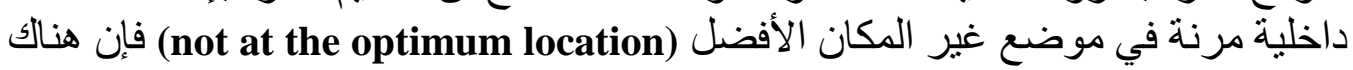

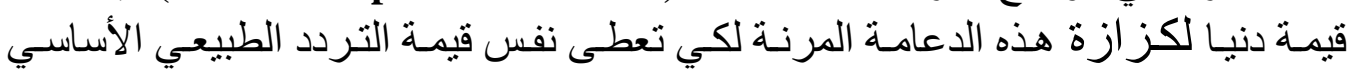

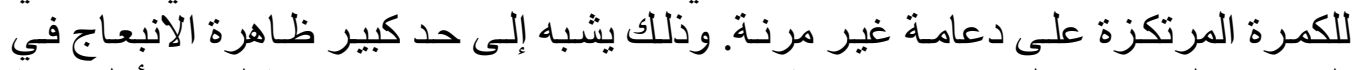

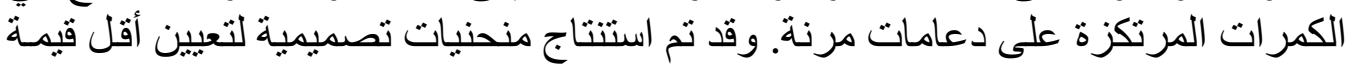

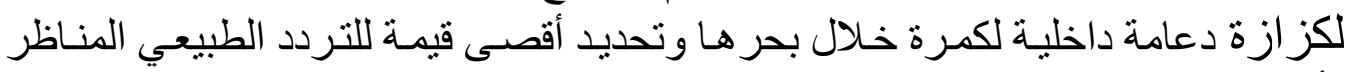
لأربعة ظروف حدية مختلفة. 